\title{
INFLUÊNCIA DA TEMPERATURA NA GERMINAÇÃO DE SEMENTES DE CUBIU (Solanum sessiliflorum Dunal) NO ESCURO ${ }^{1}$
}

\author{
Lenoir Alves dos SANTOS ${ }^{2}$, Carlos Roberto BUENO ${ }^{2}$, Charles R. CLEMENT ${ }^{2}$
}

RESUMO - Objetivou-se determinar a influência de diferentes temperaturas constantes (20, 25,30 e $\left.35^{\circ} \mathrm{C}\right)$ e alternadas de $12 / 12$ horas $\left(20: 30^{\circ} \mathrm{C}\right.$ e $\left.20: 35^{\circ} \mathrm{C}\right)$ na germinação de sementes de uma população cultivada de cubiu (Solanum sessiliflorum Dunal) na ausência de luz. Foram avaliadas a percentagem de germinação e o indice de velocidade de germinação (I.V.G.). Os tratamentos com temperaturas alternadas foram similares, com $68,7 \%$ e $65,5 \%$ de germinação e com 33,7 e 32,7 de I.V.G., respectivamente. Nos tratamentos com temperaturas constantes a germinação foi baixa, com percentagens de germinação entre 0 e $1 \%$.

Palavras-chave: Alternância de temperatura, viabilidade, velocidade de germinação.

Effect of Temperature on Germination of Orinoco Apple (Solanum sessiliflorum) Seeds in the Dark

ABSTRACT - The objective of this study was to determine the influence of constant $(20,25$, 30 and $\left.35^{\circ} \mathrm{C}\right)$ and alternating $\left(12 / 12\right.$ hours: $20: 30^{\circ} \mathrm{C}$ and $\left.20: 35^{\circ} \mathrm{C}\right)$ temperatures on seed germination in a cultivated population of orinoco apple (Solanum sessiliflorum Dunal) in the absense of light. Percentage of germination and germination velocity index (G.V.I.) were evaluated. The $20: 35^{\circ} \mathrm{C}$ and $20: 30^{\circ} \mathrm{C}$ alternating temperatures presented similar germination, $68.7 \%$ and $65.5 \%$, and G.V.I., 33.7 and 32.7 , respectively. Germination at constant temperature was very much reduced, varying from 0 to $1 \%$.

Key-words: Alternating temperature, viability, germination velocity.

O cubiu (Solanum sessiliflorum Dunal) é uma solanácea herbácea, heliófila, de ciclo anual. É comum no Estado do Amazonas, onde pode ser encontrada cultivada ou subespontânea, e é mais rara no Estado do Pará (Pahlen, 1977). Os frutos são utilizados para sucos, doces, geléias, compotas e como tempero no preparo de carnes e peixes, bem como na medicina tradicional para a redução de niveis elevados de colesterol, ácido úrico e glicose no sangue (Silva Filho et al., 1996). A produção de frutos pode variar entre 40 a 140 tha quando adubada, dependendo do material genético e do manejo adotado (Pahlen,
1977; Silva Filho et al., 1996).

O conhecimento da fisiologia de germinação das sementes e sua interação com o ambiente poderia contribuir para a implantação de pomares em escala comercial, garantindo germinação uniforme e vigorosa. A germinação exige condições especificas para que as sementes consigam expressar o seu máximo vigor (Figliolia, 1984). A temperatura influencia os processos bioquímicos e físiológicos na germinação da semente, sendo um dos fatores que mais afeta a velocidade, a uniformidade e a percentagem de germinação. Pequenas diferenças de

\footnotetext{
'Parte da monografia para o título de Eng. Agr. do $1^{\circ}$ autor. Apoio financeiro do $\mathrm{CNPq}$

${ }^{2}$ Instituto Nacional de Pesquisas da Amazônia-INPA, Caixa Postal 478, 69011,970 Manaus, AM, Brasil
} 
temperatura podem causar grandes modificações na resposta germinativa da semente (Ramos \& Bianchetti, 1984). Nas sementes de espécies tropicais e subtropicais recomenda-se temperaturas constantes de 20 a $35^{\circ} \mathrm{C}$ ou alternadas de $20: 35^{\circ} \mathrm{C}$; a preferência por temperaturas alternadas nesta faixa está na semelhança com a natureza e pode acelerar a germinação em sementes não dormentes (Figliolia, 1984).

Torres (1996) encontrou a melhor germinação de tomate (Lycopersicum esculentum L.) sob alta temperatura constante $(56 \%$ de germinação a $35^{\circ} \mathrm{C}$ ). As espécies Solanum nigrum L., S. ciliatum Lam. e $S$. chloranthum DC não germinaram sob as temperaturas constantes de 15 a $30^{\circ} \mathrm{C}$, porém germinaram em todas as alternadas, com destaque para $25: 15^{\circ} \mathrm{C}$, onde a germinação foi $50 \%$ (Engelhardt et al., 1961). A germinação no cubiu inicia-se aos 9 dias após a semeadura, estabilizandose no $24^{\circ}$ dia, sob as seguintes condições naturais: temperatura média de $26,6^{\circ} \mathrm{C}$, precipitação pluviométrica de $255 \mathrm{~mm}$ no mês e $86 \%$ de umidade relativa do ar (Ferreira, 1981). O presente trabalho avaliou a influência de diferentes temperaturas alternadas e constantes na germinação de sementes de cubiu no escuro.

Frutos maduros de cubiu foram coletados ao acaso do programa de melhoramento de hortaliças nativas do Instituto Nacional de Pesquisas da Amazônia, Manaus, AM. Os frutos, com peso médio entre 50 e $100 \mathrm{~g}$, foram cortados e as sementes extraidas, lavadas em água corrente e secas em condições de laboratório por 24 horas a $22^{\circ} \mathrm{C}$, sob umidade relativa do ar de $67 \%$. Após a secagem, as sementes foram selecionadas visualmente, avaliando o tamanho normal e a cor branca; foi também observada a presença do embrião achatado, do tamanho de um ponto de caneta, de cor bege. As sementes pequenas, transparentes, manchadas e sem o ponto bege foram descartadas. As sementes selecionadas foram semeadas em seguida, não havendo armazenamento dos frutos e nem das sementes. Apesar das Regras para Análises de Sementes (Brasil, 1980) recomendar 100 sementes para estimar o peso, usou-se 1000, conforme Pahlen (1977), por tratarem-se de sementes pequenas. $\mathrm{O}$ experimento foi conduzido em câmara de germinação (modelo BOD), com precisão de $\pm 2^{\circ} \mathrm{C}$. O escuro total foi obtido por meio de 3 sacos de polietileno preto utilizado para revestir as placas de petri onde foi feita a semeadura. $\mathrm{O}$ substrato consistiu de 3 discos de papel de filtro, tipo 10 , com $9 \mathrm{~cm}$ diâmetro, em placas de petri e foi umedecido com $3 \mathrm{ml}$ de água destilada e deionizada, com reposição de $1 \mathrm{ml}$ de água por placa a cada 3 dias. As placas foram vedadas com fita adesiva, visando manter o nível de umidade interna constante. As temperaturas estudadas foram 20,25 , 30 e $35^{\circ} \mathrm{C}$ constantes, e $20: 30^{\circ} \mathrm{C}$ e $20: 35^{\circ} \mathrm{C}$ alternadas de $12 / 12$ horas. A germinação foi avaliada diariamente em sala escura, sob luz verde, contando-se as sementes germinadas 
até o vigésimo dia. Considerou-se semente germinada aquela que apresentou a protusão da radícula. Com base nos resultados diários, foi calculado o indice de velocidade de germinação (Brasil, 1980). O delineamento experimental utilizado foi inteiramente casualizado, com 6 tratamentos e 4 repetições de 50 sementes. Os valores de germinação foram transformados pelo arcoseno $((\mathrm{x}+1) / 100)^{1 / 2}$ (Banzatto, 1992) e as médias foram comparadas pelo teste de Tukey, a $5 \%$ de probabilidade.

O peso médio de 1000 sementes foi de $0,80 \pm 0,001 \mathrm{~g}$, ou seja cerca de 1.130 sementes por grama. Pahlen (1977) encontrou que o peso médio de 1000 sementes foi $1,20 \mathrm{~g}$. Atribuiu-se a diferença entre estes dois resultados à grande variabilidade genética existente em cubiu (Pahlen, 1977; Silva Filho et al., 1996) ou diferentes teores de umidade dos lotes. Do lote inicial de sementes, observou-se que $89 \%$ eram completas, possuiam embrião e coloração branca.

A percentagem final de germinação e o indice de velocidade de germinação (I.V.G.) dos tratamentos com temperaturas alternadas não diferiram significativamente entre si (Tab. 1), mas foram significativamente diferentes $\mathrm{e}$ superiores às temperaturas constantes, as quais essencialmente não promoveram a germinação. $\mathrm{O}$ mesmo ocorreu com Solanum nigrum, $S$. ciliatum e $S$. chloranthum, que não germinaram sob as temperaturas constantes a que foram expostas (Engelhardt et. al., 1961). No entanto, Santos (1996), trabalhando

Tabela 1. Médias ( \pm desvio padrão )* da percentagem de germinação e do Índice de Velocidade de Germinação (I.V.G.) de sementes de cubiu (Solanum sessiliflorum), sob influência de diferentes temperaturas constantes e alternadas no $20^{\circ}$ dia após a semeadura.

\begin{tabular}{lcccccc}
\hline & \multicolumn{6}{c}{ TRATAMENTOS } \\
\cline { 2 - 7 } & $20^{\circ} \mathrm{C}$ & $25^{\circ} \mathrm{C}$ & $30^{\circ} \mathrm{C}$ & $35^{\circ} \mathrm{C}$ & $20: 30^{\circ} \mathrm{C}$ & $20: 35^{\circ} \mathrm{C}$ \\
\hline$\%$ Germinação & $0 \mathrm{~b}$ & $0 \mathrm{~b}$ & $1,0 \pm 0,1 \mathrm{~b}$ & $0 \mathrm{~b}$ & $68,5 \pm 3 \mathrm{a}$ & $65,6 \pm 5,3 \mathrm{a}$ \\
I. V. G. & - & - & $0,7 \pm 0,1 \mathrm{~b}$ & - & $33,7 \pm 0,6 \mathrm{a}$ & $32,7 \pm 1,7 \mathrm{a}$ \\
\hline
\end{tabular}

* Na horizontal, médias seguidas de mesma letra não diferem entre si ao nível de $5 \%$, pelo teste de Tukey.

com sementes de cubiu armazenadas por cerca de 2 meses, encontrou $60 \%$ germinação em cubiu na luz e $42 \%$ no escuro, sem diferença significativa, à temperatura constante de $30^{\circ} \mathrm{C}$.

Com o tratamento $20: 30^{\circ} \mathrm{C}$, a emergência da radícula iniciou no oitavo dia e a emergência aumentou progressivamente até o $13^{\circ}$ dia, quando estabilizou-se em $68,5 \%$ de germinação (Fig. 1). O tratamento $20: 35^{\circ} \mathrm{C}$ teve uma emergência inicial mais lenta e após 12 dias mostrou um rápido incremento, estabilizando-se no $14^{\circ}$ dia com $65,6 \%$ de germinação. Supõe-se que a adaptação a temperaturas alternadas reflete as condições naturais da Amazônia, com 


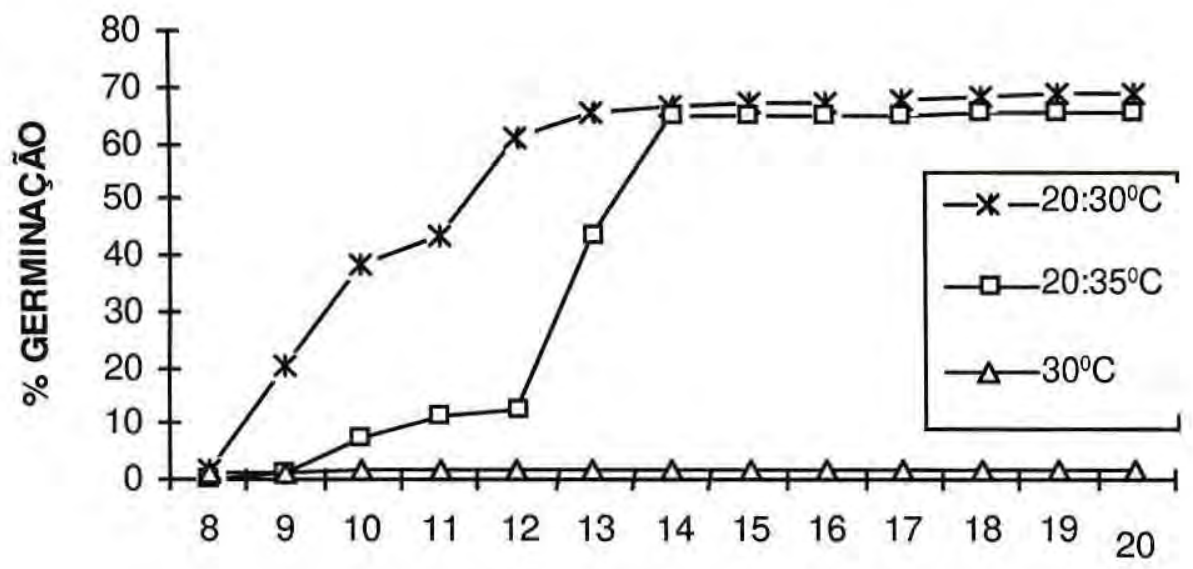

DIAS APÓS A SEMEADURA

Figura 1. Germinação cumulativa de sementes de cubiu (Solanum sessiliflorum) em função de diferentes temperaturas constantes e alternadas.

temperaturas moderadas a noite $\mathrm{e}$ quentes durante o dia.

\section{AGRADECIMENTOS}

Ao professor M.Sc. Ari Freitas Hidalgo pelo apoio e co-orientação, ao Dr. Sidney Alberto do N. Ferreira e à $\mathrm{Dr}^{\mathrm{a}}$ Isolde Dorotea Kosme Ferraz pela revisão crítica do manuscrito, e ao M.Sc. Danilo Fernandes da Silva Filho pelo material genético e as sugestões dadas.

\section{Bibliografia citada}

Banzatto, D.A. 1992, Experimentação Agricola. Fundação de Estudos e Pesquisas em Agronomia, Medicina Veterinária e Zootecnia (FUNESP), Jaboticabal. 247 p.

Brasil.1980. Regras para análises de sementes.

Ministério da Agricultura, Departamento Nacional de Produção Vegetal, Divisão de Sementes e Mudas, Brasília. 188 p.

Engelhardt, M.; Vicente, M.; Silberschmidt, K. 1961. Observações sobre a germinação de sementes de algumas espécies de solanáceas brasileiras. Anais da Academia Brasileira de Ciências, 33(1):55-68.

Ferreira, S.A.N. 1981. Condução de mudas de cubiu (Solanum topiro H. B. K.) em diferentes substratos. Monografia de Graduação, Faculdade de Ciências Agrárias, Fundação Universidade do Amazonas, Manaus. 82 p.

Figliolia, M.B. 1984. Influência da temperatura e substrato na germinação de sementes de algumas essências florestais nativas. Simpósio Internacional: Métodos de produção e controle de qualidade de sementes e mudas florestais. Universidade Federal do Paraná, Curitiba. p.193-204.

Pahlen, A. von der, 1977. Cubiu (Solanum topiro Humb. \& Bonpl.), uma fruteira da Amazônia. Acta Amazonica, 7(3):301307.

Ramos, A.; Bianchetti, A. 1984. Influência da temperatura e do substrato na germinação de sementes florestais. Simpósio Internacional: Métodos de produção $e$ controle de qualidade de sementes e mudas florestais. Universidade Federal do Paraná, Curitiba. p.252-275.

Santos, L.A. 1996. Influência de diferentes 
temperaturas na germinação de sementes de cubiu (Solanum sessiliflorum Dunal). Monografia de Graduação, Faculdade de Ciências Agrárias, Universidade do Amazonas, Manaus. 35 p.

Silva Filho, D.F.; Anunciação, C.J.; Noda, H.; Reis, O.V. 1996. Variabilidade genética em populações naturais de cubiu da Amazônia. Horticultura Brasileira, 14(1):9-14.

Torres, W. 1996. Germinación de semillas de tomate (Lycopersicum esculentum L.) a diferentes temperaturas. Cultivos Tropicales, 17(1):16-19. 